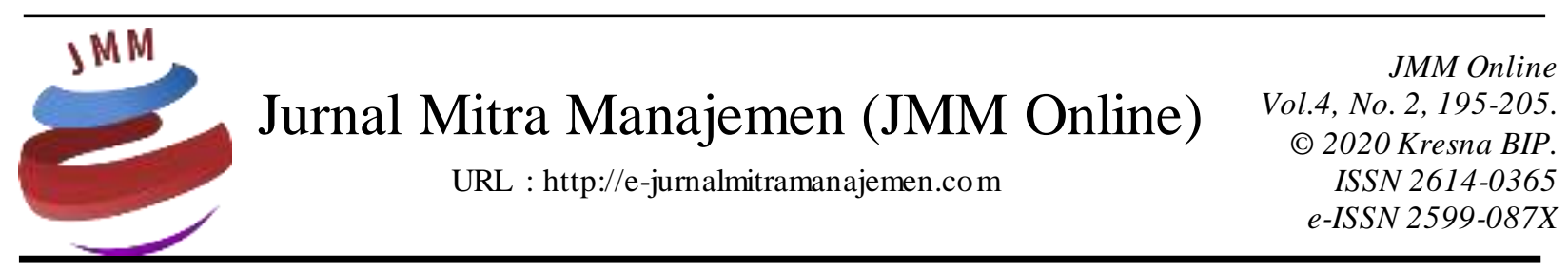

\title{
PENGARUH STRES KERJA TERHADAP KINERJA KARYAWAN (STUDI PADA PT LESTARI BUSANA ANGGUN MAHKOTA DI BAGIAN PRODUKSI)
}

\author{
Vira Sani Putri 1), Fetty Poerwita Sary ${ }^{2)}$ \\ Universitas Telkom
}

INFORMASI ARTIKEL

Dikirim : 31 Januari 2020

Revisi pertama : 03 Februari 2020

Diterima : 10 Februari 2020

Tersedia online : 27 Februari 2020

Kata Kunci : Stres Kerja, Kinerja Karyawan

Email:vsaniputri@gmail.com ${ }^{1)}$, poerwitasary@gmail.com ${ }^{2)}$

\section{ABSTRAK}

Penelitian ini dilakukan untuk mengetahui tingkat stres kerja karyawan, tingkat kinerja karyawan, dan pengaruh stres kerja terhadap kinerja karyawan di PT Lestari Busana Anggun Mahkota di Bagian Produksi. Metode penelitian menggunakan metode kuantitatif. Metode pengumpulan data dilakukan melalui penyebaran kuesioner kepada 224 responden sebagai sampel dari jumlah populasi sebanyak 507 karyawan. Kuesioneryang digunakan pada penelitian ini terdiri dari 33 pernya taan. Dalam menjelaskan hasil penelitian, teknik analisis data menggunakan analisis deskriptif, analisis linier sederhana, dan uji asumsi klasik. Hasil uji regresi menujukkan bahwa stres kerja berpengaruh signifikan negatif terhadap kinerja karyawan pada PT Lestari Busana Anggun Mahkota di Bagian Produksi. Besar pengaruh stres kerja terhadap kinerja karyawan PT Lestari Busana Anggun Mahkota di Bagian Produksi adalah sebesar 33,8\%, sisanya sebesar 66,2\% dipengaruhi oleh variabel yang tidak diteliliti pada penelitian ini. 


\section{PENDAHULUAN}

\section{Latar Belakang}

Semua perusahaan memiliki keinginan dan tujuan yang sama yaitu maju, berkembang, mendapatkan keuntungan yang maksimal dan mensejahterakan orangorang di dalam perusahaan. Salah satu cara perusahaan mendapatkan keuntungan yang maksimal adalah dengan memanfaatkan berbagai sumber daya yang dimiliki, terutama sumber daya manusia. Sumber daya manusia yang dapat berkontribusi untuk perusahaan merupakan karyawan yang berprestasi, berkompeten tinggi, dan memiliki kinerja yang baik. Kinerja yang baik merupakan kinerja yang optimal yaitu mengikuti prosedur sesuai dengan standar yang telah ditetapkan oleh perusahaan (Dewi \& Wibawa, 2016). Dalam meningkatkan kinerja karyawannya, perusahaan perlu mengetahui faktor-faktor apa saja yang dapat mempengaruhi kinerja karyawan (Oktaviani \& Darmo, 2017).

Terdapat banyak faktor yang memengaruhi karyawan agar dapat mencapai kinerja yang optimal. Menurut Mumbi dan Makori (2015) kompensasi memiliki pengaruh positif terhadap kinerja karyawan, semakin tinggi kompensasi yang didapat oleh karyawan maka akan semakin optimal pula kinerja yang diberikan karyawan untuk perusahaan. Gaya kepemimpinan, budaya organisasi, motivasi kerja, dan disiplin kerja memengaruh kinerja karyawan secara signifikan (Hidayah \& Nazaruddin, 2017). Pendapat lain menurut Iqbal et al. (2015) terdapat lima faktor yang memengaruhi kinerja karyawan yaitu pelatihan dan imbalan keuangan yang berpengaruh positif terhadap kinerja karyawan sedangkan, jam kerja, hambatan komunikasi, dan stres berpengaruh negatif terhadap kinerja karyawan. Hidayat (2016) membuktikan bahwa stres kerja berpengaruh negatif terhadap kinerja seseorang. Jika stres meningkat maka kinerja seseorang akan menurun dan sebaliknya stres kerja menurun maka kinerja seseorang akan meningkat. Tingkat stres yang rendah dapat memengaruhi karyawan untuk mencapai kinerja yang optimal.

Stres merupakan salah satu faktor yang penting, karena keseimbangan kehidupan kerja yang sehat dibutuhkan oleh karyawan untuk mencapai kinerja yang optimal oleh karena itu, penting bagi perusahaan untuk mengelola tingkat stres karyawan (Warni, 2016). Berdasarkan penelitian terdahulu, variabel stres kerja memiliki pengaruh negatif terhadap kinerja karyawan (Dewi Wibawa, 2016; Julvia, 2016; Lamb \& Kwok, 2016; Khuong \& Yen, 2016; Yunita \& Saputra, 2019; Bjaalid et al., 2019).

PT Lestari Busana Anggun Mahkota merupakan perusahaan yang bergerak di bidang garment dengan target produksi yang tinggi. Oleh karena itu, kinerja karyawan di bagian produksi merupakan hal yang penting untuk diperhatikan pada perusahaan ini karena sebagai ujung tombak dari perusahaan ini. Selain itu, stres kerja yang tidak dikelola oleh perusahaan juga akan memengaruhi kinerja karyawan. Inti bahasan pada penelitian ini adalah untuk mengetahui pengaruh stres kerja terhadap kinerja karyawan pada PT Lestari Busana Anggun Mahkota di Bagian Produksi.

\section{Rumusan Masalah}


Dalam meningkatkan kinerja karyawan, perusahaan perlu memerhatikan faktor-faktor yang memengaruhi kinerja karyawan seperti gaya kepemimpinan, motivasi karyawan, kompensasi, lingkungan kerja karyawan, beban pekerjaan, pelatihan, dan salah satunya adalah stres yang dialami saat bekerja. Faktor-faktor tersebut dapat memengaruhi kinerja karyawan dalam menyelesaikan tugas pekerjaannya. Berdasarkan penelitian terdahulu, kinerja karyawan dapat meningkat bila stres kerja yang dialami masih pada batas rendah hingga sedang. Artinya, stres kerja dan kinerja memiliki hubungan negatif. Stres kerja yang dialami oleh karyawan bila dikelola dengan baik oleh perusahaan akan meningkatkan kinerja karyawan.

\section{Tujuan Penelitian}

Berdasarkan permasalahan tersebut, tujuan dari penelitian ini adalah untuk mengetahui seberapa tinggi tingkat stres yang dialami karyawan pada PT Lestari Busana Anggun Mahkota di Bagian Produksi, bagaimana kinerja karyawan pada PT Lestari Busana Anggun Mahkota di Bagian Produksi, dan seberapa besar pengaruh stres kerja terhadap kinerja karyawan pada pada PT Lestari Busana Anggun Mahkota di Bagian Produksi.

\section{KAJIAN PUSTAKA Stres Kerja}

Stres merupakan kondisi psikologis yang tidak menyenangkan yang menekan diri dan jiwa seseorang di luar batas kemampuan, jika dibiarkan tanpa ada solusi akan berdampak pada kesehatan. Stres tidak timbul begitu saja melainkan terdapat sebabsebab stres yang umumnya diikuti oleh faktor peristiwa yang memengaruhi kejiwaan seseorang, interpretasi yang merupakan suatu evaluasi mental atas suatu peristiwa dalam arti bagaimana hal tersebut mengancam aspek pribadi seseorang, dan konsekuensi negatif ditandai dengan munculnya penderitaan jasmani dan mental atau emosional seseorang (Robbins dan Judge, 2017; Fahmi, 2016).

Faktor-faktor stres kerja bisa muncul dari mana saja, baik dari diri sendiri, organisasi, dan lingkungan tanpa melihat waktu kapan stres tersebut akan terjadi. Faktor internal datang dari diri sendiri seperti tekanan yang dialami seseorang pada masalah keluarga, konflik dengan dirinya sendiri, konflik dengan rekan kerja, dan masalah ekonomi. Sedangkan, faktor eksternal disebabkan dari luar peristiwa diri sendiri seperti tuntutan pekerjaan dari atasan yang terlalu memaksa, beban pekerjaan yang terlalu berat, lingkungan kerja yang tidak mendukung, dan ketidakpastian ekonomi (Fahmi, 2016; Robbins \& Judge, 2017; Badeni, 2017).

Terdapat beberapa dampak yang ditimbulkan oleh stres kerja. Dampak dari stres kerja dapat berupa dampak positif dan negatif. Dampak positif dari stres kerja adalah dapat meningkatkan motivasi karyawan, menginspirasi karyawan untuk hidup lebih baik, dan dapat menstimulus karyawan untuk bekerja lebih giat. Sedangkan, dampak negatif dari stres, yaitu (1) dampak subjektif seperti kegelisahan, depresi, kehilangan kesabaran, dan merasa kesepian; (2) dampak perilaku seperti peledakan emosi dan perilaku impulsif dalam bekerja; (3) dampak kognitif seperti tingkat konsentrasi yang menurun dan ketidakmampuan untuk mengambil keputusan yang sehat; (4) dampak fisiologis seperti denyut jantung dan tekanan darah meningkat, 
berkeringat, mulut kering, tubuh panas dingin, dan kecanduan glukosa darah meningkat; (5) dampak kesehatan seperti sulit tidur, sakit kepala, dan mimpi buruk, dan (6) dampak organisasi, yaitu terasing dari rekan kerja, produktivitas menurun, menurunnya rasa ikatan kerja dan loyalitas terhadap instansi (Priansa, 2017b).

Penelitian ini menggunakan dimensi yang dipaparkan oleh Enhassi et al. (2015) yang memiliki empat dimensi yaitu stres yang disebabkan oleh organisasi, stres yang disebabkan oleh tuntutan tugas, stres yang disebabkan oleh individu, dan stres yang disebabkan oleh lingkungan kerja.

\section{Kinerja Karyawan}

Kinerja merupakan gambaran mengenai hasil kerja yang dicapai oleh seseorang dalam menjalankan dan mengerjakan tugas pekerjaan yang diberikan dan seberapa banyak kontribusi yang diberikan kepada organisasi. Bisa disebut juga sebagai tingkat keberhasilan karyawan dalam menyelesaikan pekerjaan yang diberikan perusahaan yang merupakan perwujudan dari kemampuan yang dimiliki. Hasil kerja yang dicapai dapat berupa kuantitas maupun kualitas dalam suatu organisasi sesuai dengan tanggung jawab yang diberikan (Sudaryono et al., 2018; Priansa, 2017a).

Banyak manfaat yang didapatkan dari penilaian kinerja, salah satunya adalah membantu organisasi untuk membuat keputusan bagaimana memperlakukan karyawannya dalam hal jabatan yang diberikan, kebutuhan pelatihan dan pengembangan, dan pemutusan hubungan kerja. Penilaian kinerja yang dilakukan dapat memberikan informasi untuk organisasi bagaimana keterampilan dan kompetensi karyawan sehingga program perbaikan dapat dikembangkan dan gaji yang pantas. Selain itu, penilaian kinerja juga bermanfaat bagi perencanaan kebijakan-kebijakan organisasi seperti penyesuaian kompensasi, pengambilan keputusan untuk rotasi; mutasi; promosi; dan alih jabatan, membantu diagnosis terhadap kesalahan disain karyawan, mendapatkan feedback yang akurat terkait kinerja sebelumnya, dan untuk kepentingan penelitian kepegawaian. (Robbins dan Judge, 2017; Sulistiyani dan Rosidah, 2018; Sudaryono et al. 2018).

Penelitian ini menggunakan dimensi yang dipaparkan oleh Pawirosumarto et al. (2017) yang memiliki enam dimensi yaitu kualitas kerja, kuantitas tenaga kerja, efisiensi waktu, efektivitas kerja, kebutuhan dalam pengawasan, dan pengaruh diri.

\section{Hubungan Stres Kerja dengan Kinerja Karyawan}

Menurut Robbins dan Judge (2017) stres kerja dan kinerja merupakan dua hal yang saling mempengaruhi dan berpengaruh. Tingkat stres yang rendah hingga sedang memiliki dampak yang baik untuk kinerja, yaitu kinerja menjadi optimal. Umumnya karyawan melakukan tugasnya secara lebih baik dan cepat bila sedikit stres yang dirasakan. Akan tetapi, bila stres yang dialami oleh karyawan tinggi dengan tuntutan tugas yang tidak bisa dipenuhi, maka akan menghasilkan kinerja yang rendah. Intensitas stres dapat berlanjut hingga ke level yang tertinggi bila tidak diperhatikan, dalam jangka panjang tingkat stres sedang akan berlanjut ke tingkat stres tinggi yang mengakibatkan penurunan kinerja.

Terdapat beberapa penelitian yang mengkaji terkait hubungan antara stres kerja dan kinerja karyawan. Penelitian yang dilakukan oleh Dewi dan Wibawa (2016) di 
Bali mendapatkan hasil bahwa stres kerja berpengaruh negatif dan signifikan terhadap kinerja karyawan. Hasil penelitian Zafar et al. (2015) yang dilakukan di Gujranwala, Pakistan menyatakan bajwa stress kerja berpengaruh positif terhadap kinerja karyawan. Lamb dan Kwok (2016) yang melakukan penelitian di Wellington, New Zealand menemukan hasil bahwa faktor-faktor yang terdapat pada stres kerja seperti kenyamanan lingkungan, pencahayaan, kebisingan, dan ukuran tuntutan kerja dapat secara signifikan mengurangi kinerja dan kesejahteraan kerja karyawan. Sejalan dengan penelitian Khuong dan Yen (2016) di Vung Tau, Vietnam yang juga mengemukakan bahwa stres kerja berpengaruh negatif terhadap kinerja karyawan.

Berdasarkan penjelasan di atas, maka kerangka pemikiran dalam penelitian ini adalah sebagai berikut.

\section{Gambar 1. Kerangka Pemikiran}

\begin{tabular}{|c|c|}
\hline Stres Kerja & Kinerja Karyawan \\
\hline 1. Organizational & 1. Work Quality \\
\hline Stressors & 2. Labor Quantity \\
\hline 2. Task Stressors & 3. Time Efficiency \\
\hline 3. Personnel Stressors & 4. Work Effectiveness \\
\hline 4. Work Environment & 5. Supervision Needs \\
\hline Stressors & 6. Self-Influence \\
\hline Variabel $\mathrm{X}$ & Variabel Y \\
\hline Enhassi et al. (2015) & Pawirosumarto et al. (2017) \\
\hline
\end{tabular}

Sumber: Hasil Olahan Penulis (2019)

Berdasarkan uraian penelitian-penelitian terdahulu yang dilakukan oleh para ahli, penulis menyimpulkan bahwa stres kerja berpengaruh negatif terhadap kinerja karyawan. Artinya, semakin tinggi stres kerja yang dialami oleh karyawan maka kinerja karyawan akan menurun, sebaliknya apabila tingkat stres kerja karyawan rendah maka kinerja karyawan akan meningkat. Penulis menentukan hipotesis pada penelitian ini, yaitu:

$\mathbf{H}_{1}$ : Terdapat pengaruh signifikan negatif antara stres kerja terhadap kinerja karyawan PT Lestari Busana Anggun Mahkota di Bagian Produksi.

\section{METODE PENELITIAN \\ Jenis Penelitian}

Metode penelitian yang digunakan pada penelitian ini adalah metode kuantitatif dengan jenis penelitian yaitu penelitian kausal. Berdasarkan tujuannya, penelitian ini adalah deskriptif. Berdasarkan waktu pelaksanaannya, penelitian ini termasuk penelitian cross section. Berdasarkan keterlibatan peneliti, penelitian ini tidak mengintervensi data. 


\section{Tempat dan Waktu Penelitian}

Penelitian ini berlokasi di PT Lestari Busana Anggun Mahkota di Jalan Taruma Negara, Pisangan, Ciputat Timur, Tangerang Selatan. Objek penelitian ini adalah karyawan PT Lestari Busana Anggun Mahkota pada bagian produksi. Penelitian ini dilaksanakan mulai bulan Agustus 2019 hingga bulan Januari 2020.

\section{Teknik Pengumpulan Data}

Penelitian ini menggunakan data primer dan data sekunder. Data primer diperoleh melalui hasil wawancara dan kuesioner yang dibagikan dan dijawab oleh responden dengan hasil yang sudah dianalisis terlebih dahulu. Data sekunder pada penelitian ini diperoleh melalui data yang telah diterbitkan dan digunakan oleh perusahaan yang menjadi objek penelitian. Pengukuran kedua variabel dalam penelitian mengenai stres kerja memiliki 20 item pernyataan dan 13 item pernyataan terkait kinerja karyawan. Penelitian ini menggunakan metode convenience sampling untuk menentukan sampel dari populasi karyawan di PT Lestari Busana Anggun Mahkota di Bagian Produksi yang berjumlah 507 orang, dengan menggunakan rumus slovin didapatkan sampel sebanyak 224 orang.

\section{Teknik Analisis Data}

Penelitian ini menggunakan uji reliabilitas dengan menggunakan Cronbach's Alpha. Nilai yang dihasilkan untuk variabel stres kerja $(\mathrm{X})$ adalah sebesar sebesar 0,904 yang artinya nilai tersebut lebih besar dari nilai Alpha 0,60. Sedangkan, variabel terikat (Y) kinerja karyawan mendapat hasil sebesar 0,744 yang artinya nilai tersebut lebih besar dari nilai Alpha 0,60. Hasil uji reliabilitas tersebut berada pada derajat keandalan luar biasa bagus, sehingga layak digunakan sebagai instrumen ukuran untuk penelitian ini.

Teknik analisis data yang digunakan dalam penelitian ini adalah analisis deskriptif, analisis regresi linier sederhana dengan uji asumsi klasik menggunakan uji normalitas dan uji heteroskedastisitas. Analisis regresi linier sederhana digunakan dalam penelitian ini untuk mengukur pengaruh stres kerja terhadap kinerja karyawan. Selain itu, analisis koefisien determinasi dan uji hipotesis dilakukan pula pada penelitian ini.

Berikut merupakan aspek demografi dari penelitian ini.

Tabel 1. Aspek Demografi

\begin{tabular}{|l|l|c|c|}
\hline \multicolumn{1}{|c|}{ Kriteria } & \multicolumn{1}{|c|}{ Subkriteria } & $\begin{array}{c}\text { Jumlah } \\
\text { Responden }\end{array}$ & Persentase \\
\hline \multirow{3}{*}{ Jenis Kelamin } & Laki-laki & 89 & $39.73 \%$ \\
\cline { 2 - 4 } & Perempuan & 135 & $60.27 \%$ \\
\hline \multirow{4}{*}{ Usia } & $<25$ Tahun & 45 & $20.09 \%$ \\
\cline { 2 - 4 } & 25 - 30 Tahun & 107 & $47.77 \%$ \\
\cline { 2 - 4 } & $>30-35$ Tahun & 43 & $19.20 \%$ \\
\cline { 2 - 4 } & $>35-40$ Tahun & 18 & $8.04 \%$ \\
\cline { 2 - 4 } & $>40$ Tahun & 11 & $4.91 \%$ \\
\hline
\end{tabular}


Lanjutan Tabel 1. Aspek Demografi

\begin{tabular}{|l|l|c|c|}
\hline \multirow{4}{*}{ Status } & Menikah & 124 & $55.36 \%$ \\
\cline { 2 - 4 } & Belum Menikah & 64 & $28.57 \%$ \\
\cline { 2 - 4 } & Cerai & 36 & $16.07 \%$ \\
\hline \multirow{5}{*}{ Pendidikan } & SMA/SMK & 197 & $87.95 \%$ \\
\cline { 2 - 4 } & D1 - D3 & 19 & $8.48 \%$ \\
\cline { 2 - 4 } & S1 & 8 & $3.57 \%$ \\
\cline { 2 - 4 } & S2/S3 & 0 & $0.00 \%$ \\
\hline Lama Bekerja & $<1$ Tahun & 34 & $15.18 \%$ \\
\cline { 2 - 4 } & $1-5$ Tahun & 105 & $46.88 \%$ \\
\cline { 2 - 4 } & $>$ 5 Tahun & 85 & $37.95 \%$ \\
\hline
\end{tabular}

Sumber: Hasil Olahan Penulis (2020)

\section{HASIL PENELITIAN DAN PEMBAHASAN \\ Uji Normalitas}

Uji normalitas dilakukan untuk melihat apakah data pada penelitian ini terdistribusi normal atau tidak. Oleh karena itu, uji normalitas merupakan uji yang dilakukan terlebih dahulu sebelum uji yang lain. Pada penelitian ini, untuk melakukan uji normalitas digunakan uji Kolmogorov-Smirnov. Berikut merupakan hasil dari pengujian normalitas menggunakan uji Kolmogorov-Smirnov.

Tabel 2. Uji Normalitas Menggunakan Uji Kolmogorov-Smirnov

\begin{tabular}{|l|r|}
\hline \multicolumn{2}{|c|}{ One-Sample Kolmogorov-Smirnov } \\
\hline Kolmogorov-Smirnov $Z$ & .866 \\
\hline Asymp. Sig. (2-tailed) & .441 \\
\hline
\end{tabular}

Sumber: Hasil Penelitian, diolah (2020)

Berdasarkan Tabel 2 dapat disimpulkan bahwa data pada penelitian ini terdistribusi normal. Hal ini dapat dilihat dari nilai signifikansi Asymp. Sig. (2-tailed) sebesar 0,441 yang lebih besar dari 0,05, artinya data terdistribusi normal.

\section{Uji Heteroskedastisitas}

Uji selanjutnya yang dilakukan adalah uji heteroskedastisitas. Pada penelitian ini uji heteroskedastisitas dilakukan menggunakan uji Glejser. Berikut merupakan hasil dari uji Glejser.

\section{Tabel 3. Uji Heteroskedastisitas Menggunakan Uji Glejser}

\begin{tabular}{|l|l|r|}
\hline \multicolumn{2}{|c|}{ Coefficients $^{\mathbf{a}}$} \\
\hline \multicolumn{2}{|c|}{ Model } & \multicolumn{1}{c|}{ Sig. } \\
\hline \multirow{2}{*}{1} & (Constant) & .070 \\
\cline { 2 - 3 } & Stres Kerja & .304 \\
\hline
\end{tabular}

Sumber: Hasil Penelitian, diolah (2020)

Berdasarkan Tabel 3 dengan menggunakan uji Glejser dapat terlihat bahwa nilai signifikansi variabel stres kerja $(X)>0,05$, yaitu sebesar 0,304. Dapat 
disimpulkan bahwa model regresi tidak mengandung heteroskedastisitas atau uji heteroskedastisitas terpenuhi karena 0,304>0,05.

\section{Uji Analisis Regresi Linier Sederhana}

Model analisis pada penelitian ini menggunakan analisis regresi linier sederhana. Berikut merupakan hasil dari analasis menggunakan regresi linier sederhana.

Tabel 4. Analisis Regresi Linier Sederhana

\begin{tabular}{|l|l|r|r|}
\hline \multicolumn{3}{|c|}{ Coefficients $^{\mathbf{a}}$} \\
\hline \multicolumn{2}{|l|}{ Model } & \multicolumn{1}{c|}{ B } & \multicolumn{1}{c|}{ Sig. } \\
\hline \multirow{2}{*}{1} & (Constant) & 67.465 & .000 \\
\cline { 2 - 4 } & Stres Kerja & -.360 & .000 \\
\hline
\end{tabular}

Sumber: Hasil Penelitian, diolah (2020) berikut.

Berdasarkan Tabel 4 dapat persamaan pada penelitian ini adalah sebagai

$$
\mathrm{Y}=\alpha+\mathrm{bX}=67.465-0,360
$$

Berdasarkan persamaan di atas dapat disimpulkan bahwa koefisien regresi untuk variabel bebas (X) bernilai negatif dengan konstanta (b) sebesar 67.465 artinya ketika terjadi peningkatan stres sebesar satu satuan, maka kinerja karyawan akan menurun sebesar 0,360 satu satuan. Tanda (-) negatif pada hasil yang keluar menunjukkan adanya arah hubungan yang berlawanan. Sehingga, -0,360 menyatakan bahwa jika tingkat stres kerja semakin menurun maka kinerja karyawan akan semakin meningkat begitu pula sebaliknya, ketika tingkat stres kerja meningkat maka kinerja karyawan akan semakin menurun.

\section{Uji Koefisien Determinasi}

Selanjutnya, dilakukan uji koefisien determinasi dengan tujuan untuk mengetahui seberapa besar pengaruh variabel independen terhadap variabel dependen. Berikut merupakan hasil dari uji koefisien determinasi.

Tabel 5. Uji Koefisien Determinasi
\begin{tabular}{|l|r|r|}
\hline \multicolumn{3}{|c|}{ Model Summary } \\
\hline Model & R & R Square \\
\hline 1 & $.581^{\mathrm{a}}$ & .338 \\
\hline
\end{tabular}

Sumber: Hasil Penelitian, diolah (2020)

Berdasarkan Tabel 5 terlihat bahwa nilai koefisien korelasi atau $\mathrm{R}$ adalah sebesar 0,581 dan nilai koefisien determinasi atau R Square adalah sebesar 0,338. Sehingga, dapat disimpulkan bahwa pengaruh stres kerja sebagai variabel independen terhadap kinerja karyawan sebagai variabel dependen adalah sebesar 33,8\%, sisanya sebesar 66,2\% variabel dependen dipengaruhi oleh faktor lain selain stres kerja yang tidak dilibatkan dalam penelitian ini.

\section{Uji Hipotesis}

Uji hipotesis dilakukan untuk mengukur pengaruh yang timbul antara variabel independen yaitu stres kerja dan variabel dependen yaitu kinerja karyawan PT Lestari di Bagian Produksi. Untuk melakukan uji hipotesis pada penelitian ini, penulis 
menggunakan program SPSS 20. Berikut merupakan langkah-langkah pengujian hipotesis.

1. Menentukan hipotesis.

Pada penelitian ini hipotesis yang digunakan adalah sebagai berikut.

H0: Tidak terdapat pengaruh signifikan negatif antara stres kerja terhadap kinerja karyawan.

H1: Terdapat pengaruh signifikan negatif antara stres kerja terhadap kinerja karyawan.

2. Menentukan thitung.

$\mathrm{T}$ hitung dapat dilihat dari hasil output nilai koefisien regresi linier sederhana. Diketahui bahwa nilai t hitung adalah sebesar 10,644.

3. Menentukan statistik tabel atau tabel.

Nilai t tabel dari tabel distribusi dengan $\alpha=0,05$ pada pengujian dua arah dengan jumlah data sebanyak 224 adalah sebesar 1,971.

4. Kriteria pengambilan keputusan.

- Berdasarkan statistik hitung dengan statistik tabel

Jika t Hitung < Statistik t Tabel, maka H0 diterima

Jika t Hitung > Statistik t Tabel, maka H0 ditolak

- Berdasarkan probabilitas

Jika probabilitas $>0,025$, maka $\mathrm{H} 0$ diterima

Jika probabilitas <0,025, maka H0 ditolak

5. Membuat keputusan berdasarkan hasil pengujian

Diketahui bahwa nilai $\mathrm{t}$ hitung > t tabel yaitu 10,644 > 1,971 dan probabilitas < 0,025 yaitu $0,000<0,025$ sehingga $\mathrm{H} 0$ ditolak dan $\mathrm{H} 1$ diterima. Dapat disimpulkan bahwa variabel stres kerja memiliki pengaruh yang signifikan terhadap variabel kinerja karyawan di PT Lestari Bagian Produksi.

\section{KESIMPULAN DAN SARAN \\ Kesimpulan}

Penelitian ini melakukan studi mengenai stres kerja terhadap kinerja karyawan pada PT Lestari Busana Anggun Mahkota di Bagian Produksi. Penelitian ini dilakukan untuk mengetahui tingkat stres kerja karyawan, tingkat kinerja karyawan, dan pengaruh stres kerja terhadap kinerja karyawan. Data pada penelitian ini diperoleh melalui penyebaran kuesioner kepada 224 karyawan PT Lestari Busana Anggun Mahkota di Bagian Produksi.

Berdasarkan hasil pengujian yang diperoleh dari tanggapan responden pada stres kerja, mendapatkan hasil persentase sebesar 56,25\% atau berada pada kategori sedang. Artinya, tingkat stres kerja yang dialami oleh karyawan PT Lestari Busana Anggun Mahkota di Bagian Produksi tidak tinggi dan juga tidak rendah. Selanjutnya, berdasarkan hasil pengujian yang diperoleh dari tanggapan responden pada kinerja karyawan mendapatkan hasil persentase sebesar 70,98\% atau berada pada kategori tinggi. Artinya, berdasarkan persepsi karyawan, tingkat kinerja yang mereka miliki sudah tinggi atau sudah baik. 


\section{Saran}

Dalam usaha menurunkan tingkat stres kerja karyawan, perusahaan hendaknya lebih memerhatikan beban pekerjaan setiap karyawan agar tidak berlebihan dengan cara memberikan beban pekerjaan yang sama atau sesuai dengan porsi masing-masing dari tiap-tiap karyawannya. Selain itu, perusahaan dapat meminimalisir kebisingan yang dapat mengganggu konsentrasi karyawan. Perusahaan perlu mengetahui kebisingan tersebut datangnya dari mana. Setelah mengetahui sumber dari kebisingan tersebut, hendaknya segera melakukan sesuatu untuk mengurangi kebisingan tersebut. Jika sumber kebisingan berasal dari mesin produksi, periksa mesin tersebut apakah dalam keadaan baik atau tidak dan jika memungkinkan mesin tersebut diganti dengan mesin yang tidak telalu bising. Bila perlu, perusahaan dapat menyediakan alat pelindung pendengaran agar karyawan tetap dapat bekerja dengan konsentrasi penuh.

\section{DAFTAR PUSTAKA}

Badeni. 2017. Kepemimpinan dan Perilaku Organisasi (Cet. 3). Bandung, Indonesia: Alfabeta.

Bjaalid, G., Olsen, E., Melberg, K., \& Mikkelsen, A. 2019. Institutional Stress and Job Performance among Hospital Employees. International Journal of Organizational Analysis. doi: http//dx.doi.org/10.1108/IJOA-10-2018-1560

Dewi, C. I. A. S., \& Wibawa, I. M. A. 2016. Pengaruh Stres Kerja dan Motivasi Kerja terhadap Kinerja Karyawan pada PT. BPD Bali Cabang Ubud. E- Jurnal Manajemen Unud, 5(12), 7583-7606. Diambil dari https//ojs.unud.ac.id

Enhassi, A., El-Rayyes, Y., \& Alkilani, S. 2015. Job Stress, Job Burnout, and Safety Performance in The Palestinian Construction Industry. Journal of Financial Management of Property and Construction, 20(2), 170-178. doi: https://doi.org/10.1108/JFMPC-01-2015-0004

Fahmi, I. 2016. Manajemen Sumber Daya Manusia: Teori dan Aplikasi (Cet. 1). Bandung, Indonesia: Alfabeta.

Hidayah, R. U., \& Nazaruddin, I. 2017. The Effect of Leadership Style, Work Motivation, Organizational Culture and Job Discipline on Employees Performance. ICoSI 2014, 255-262. https://doi.org/10.1007/978-981-287661-4_26

Iqbal, A., Ijaz, M., Latif, F., \& Mushtaq, H. 2015. Factors affecting the employee's performance: A case study of banking sector in Pakistan. European Journal of Business and Social Sciences, 4(8), 309-318. Diambil dari http $/ /$ www.ejbss.com

Julvia, C. 2016. Pengaruh Stres Kerja dan Konflik Kerja terhadap Kinerja Karyawan. Jurnal Ilmiah Manajemen Bisnis, 16(1), 59-72. Diambil dari http $/ /$ ejournal.ukrida.ac.id

Khuong, M. N., \& Yen, V. H. 2016. Investigate The Effects of Job Stress on Employee Job Performance - A Case Study at Dong Xuyen Industrial Zone, Vietnam. International Journal of Trade, Economics and Finance, 7(2), 31-37. doi: 10.18178/ijtef.2016.7.2.495 
Lamb, S., \& Kwok, K. C. S. 2016. A Longitudinal Investigation of Work Environment Stressors on The Performance and Wellbeing of Office Workers. Applied Ergonomics, 52, 104-111. doi: https//doi.org/10.1016/j.apergo.2015.07.010

Mumbi, E. G., \& Makori, M. 2015. Influence of Employees Motivation on Organizational Performance in Government Ministries in Kenya: A Case of Ministry, of Agriculture, Livestock and Fisheries. Strategic Journal of Business \& Change Management, 2(86), 1119-1163. Diambil dari http $/ /$ strate gic journals.com

Oktaviani, E., \& Darmo, I. S. 2017. Pengaruh Pelatihan dan Motivasi Kerja terhadap Kinerja Pegawai Sekretariat Direktorat Jenderal Pengelolaan Pembiayaan dan Risiko Kementrian Keuangan. Jurnal Riset Manajemen dan Bisnis (JRMB) Fakultas Ekonomi UNIAT, 2(3), 373-380. doi: https://doi.org/10.36226/jrmb.v2i3.71

Pawirosumarto, S., Sarjana, P. K., \& Gunawan, R. 2017. The Effect of Work Environment, Leadership Style, and Organizational Culture towards Job Satisfaction and Its Implication towards Employee Performance in Parador Hotels and Resorts, Indonesia. International Journal of Law and Management, 59(6), 1337-1358. doi: https://doi.org/10.1108/IJLMA-10-2016-0085

Priansa, D. J. 2017a. Manajemen Kinerja Kepegawaian (Cet. 1). Bandung, Indonesia: CV Pustaka Setia.

Priansa, D. J. 2017b. Perilaku Organisasi Bisnis (Cet. 1). Bandung, Indonesia: Alfabeta.

Robbins, S. P., \& Judge, T. A. 2017. Organizational Behavior (Ed. 17). Amerika Serikat: Pearson.

Sudaryono, Y., Aribowo, A., \& Sofiati, N. A. 2018. Manajemen Sumber Daya Manusia, Kompensasi Tidak Langsung dan Lingkungan Kerja Fisik (Ed. 1). Yogyakarta, Indonesia: ANDI.

Sulistiyani, A. T., \& Rosidah. 2018. Manajemen Sumber Daya Manusia: Pendekatan Teoretik dan Praktik untuk Organisasi Publik (Cet. 1). Yogyakarta, Indonesia: GAVA MEDIA.

Warni, S. 2016. Mengelola Stress di Tempat Kerja. Zahir Accounting. Diambil dari https://zahiraccounting.com/id/blog/mengelola-stress-di-tempat-kerja/

Yunita, P. I., \& Saputra, I. G. N. W. H. 2019. Millenial Generation in Accepting Mutations: Impact on Work Stress and Employee Performance. International Journal of Social Sciences and Humanities, 3(1), 102-114. doi: https://doi.org/10.29332/ijssh.v3n1.268

Zafar, Q., Ali, A., Hameed, T., Ilyas, T., \& Younas, H. I. 2015. The Influence of Job Stress on Employees Performance in Pakistan. American Journal of Social Science Research, 1(4), 221-225. Diambil dari http:/aiscience.org 